\title{
Burden of rheumatoid arthritis on patients' work productivity and quality of life
}

\author{
Ricardo Machado Xavier ${ }^{1 *}$ (D), Cristiano Augusto Freitas Zerbini ${ }^{2}$, Daniel Feldman Pollak ${ }^{3}$, \\ Jorge Luis Alberto Morales-Torres ${ }^{4}$ (D) Philippe Chalem5 ${ }^{5}$ José Fernando Molina Restrepo ${ }^{6}$, Javier Arnaldo Duhau ${ }^{7}$, \\ Jacqueline Rodríguez Amado ${ }^{8}$, Maurício Abello ${ }^{9}$, Maria Celina de la Vega ${ }^{10} \mathbb{B}^{\mathbb{D}}$, Adriana Pérez Dávila $^{11}$, \\ Priscila Martin Biegun ${ }^{12}$, Maysa Silva Arruda ${ }^{12}$ and Cesar Ramos-Remus ${ }^{13}$ (D)
}

\begin{abstract}
Background: To determine the burden of Rheumatoid Arthritis (RA) on patients' work productivity and health related quality of life (HRQoL), and examine the influence of several exposure variables; to analyze the progression of RA over 1 year and its impact on work productivity and HRQoL.

Methods: International multicenter prospective survey including patients in 18 centers in Argentina, Brazil, Colombia and Mexico with diagnosis of RA and aged between 21-55 years. The following standard questionnaires were completed at baseline and throughout a 1-year follow-up: WPAI:RA, WALS, WLQ-25, EQ-5D-3 L and SF-36. Clinical and demographic variables were also collected through interview.

Results: The study enrolled 290 patients on baseline visit. Overall mean scores at baseline visit were: WPAl:RA (presenteeism) $=29.5 \%(\mathrm{SD}=28.8 \%)$; WPAl:RA (absenteeism) $=9.0 \%(\mathrm{SD}=23.2 \%)$; WPAl:RA (absenteeism and presenteeism $)=8.6 \%(\mathrm{SD}=22.6 \%) ; \mathrm{WALS}=9.0(\mathrm{SD}=6.1) ; \mathrm{WLQ}-25=7.0 \%(\mathrm{SD}=5.1 \%) ;$ SF-36 Physical Scale $=39.1$ $(\mathrm{SD}=10.3)$ and Mental Scale $=45.4(\mathrm{SD}=11.3) ; \mathrm{EQ}-5 \mathrm{D}-3 \mathrm{~L}$ VAS $=69.8(\mathrm{SD}=20.4)$ and $\mathrm{EQ}-5 \mathrm{D}-3 \mathrm{~L}$ index $=0.67(\mathrm{SD}=$ 0.23). Higher educational levels were associated with better results in WLQ-25, while previous orthopedic surgeries reduced absenteeism results of WPAI:RA and work limitations in WLQ-25. Higher disease duration was associated with decreased HRQoL. Intensification of disease activity was associated with decreased work productivity and HRQoL, except in WLQ-25. In the longitudinal analysis, worsening in disease activity was associated with a decrease in both work productivity and HRQoL.

Conclusions: RA patients are dealing with workplace disabilities and limitations and loss in HRQoL, and multiple factors seems to be associated with this. Worsening of disease activity further decreased work productivity and HRQoL, stressing the importance of disease tight control.
\end{abstract}

Keywords: Rheumatoid arthritis, Quality of life, Work performance, Surveys, Latin America

\section{Introduction}

Rheumatoid Arthritis (RA) is an autoimmune disease that causes chronic inflammation and proliferation in the synovial tissue of joints, leading to cartilage damage and joint destruction [1-3]. Irreversible damage occurs early and continue throughout the patient's life [4-6]. RA affects approximately $1 \%$ of the United States (US)

\footnotetext{
* Correspondence: rxavier10@gmail.com

${ }^{1}$ Universidade Federal do Rio Grande do Sul, Hospital de Clínicas de Porto Alegre, Porto Alegre, Brazil

Full list of author information is available at the end of the article
}

population, and this prevalence varies from 0.4 to $1.6 \%$ in Latin America population [7-9].

Since RA is not curable, the goals of RA therapy are to reach disease remission or to achieve low disease activity $[10,11]$. Aggressive treatment in early RA has shown to reduce functional disability over time, and positively influence employment $[12,13]$. Lack of optimal control leads to joint damage and loss of physical function, work impairment, and finally permanent work disability. Unceasing joint injury and irreversible loss of physical functioning will negatively impact patients' work performance and/or employability. A recent study 
showed that work disability rates increases in accordance to disease duration: 35,39 , and $44 \%$ after 5,10 , and 15 years of RA diagnosis, respectively [14].

There is still a need of detailed information on how RA patients are successful on preserving employability and how is the current burden of RA on work productivity in Latin America.

Therefore, this study primarily aimed to determine the burden of RA on patients' work productivity and health related quality of life (HRQoL) and to explore the impact of related variables. Additionally, the progression of RA and its impact on work productivity and HRQoL were also investigated.

\section{Methods}

\section{Study design and eligibility criteria}

PROSE RA study (Patient Reported Outcomes Survey of Employment among patients with RA) is an international multicenter prospective survey. Patients were included from May/2012 to September/2015 in 18 rheumatology public and private clinics from four Latin American countries: Argentina, Brazil, Colombia and Mexico. All sites in Argentina, Colombia and Mexico were private, while 2 out of 3 Brazilian sites were publicly funded. Patients diagnosed with RA identified in outpatient routine visits were invited to participate and were included if they met the eligibility criteria: Age between 21 and 55 years (representing a working age group); documented diagnosis of RA as defined by the revised 1987 classification criteria of the American College of Rheumatology (ACR) [15]; and willing to provide informed consent to participate in the study. Patients not able to give informed consent and/or to complete the study procedures were excluded. Two different analyses were performed: cross-sectional to determine the burden of RA on patients' work productivity and HRQoL (primary) considering the baseline answers to selected patient-reported outcomes (PROs), and longitudinal over 1 year to evaluate the progression of RA and its impact on work productivity and HRQoL (secondary).

\section{Data collection}

Five study visits were performed every three months over 1-year follow-up. During each visit, participants answered an interview that assessed data about sociodemographic and clinical characteristics, lifestyle behavior, disease activity, use of Disease-Modifying Antirheumatic Drugs (DMARDs), direct medical resource utilization and medication coverage/insurance. Impact on work productivity and HRQoL was evaluated using standardized instruments: Workplace Activity Limitation Scale (WALS), Work Productivity and Activity Impairment Questionnaire - Rheumatoid Arthritis (WPAI:RA), 25-
Item Work Limitations Questionnaire (WLQ-25), 36Item Short Form Health Survey (SF-36) and EuroQol 5 Dimensions Questionnaire 3 level version (EQ-5D-3 L). All standardized questionnaires were adequately translated into Brazilian Portuguese and Spanish. Some of the instruments had already been validated with final versions reported in previous publications or by their copyright holders. [16-20] The remaining questionnaires and versions were validated within the scope of the study, using usual methods in the field.

\section{Work productivity}

WALS is a 12-item questionnaire that assesses patient's limitation at work without a recall period. Answers options consist of a 4-point Likert scale that ranges from 0 (no difficulties) to 3 (not able to do). Dimensions includes difficulty getting to and from work, lifting, working with hands, crouching/bending/kneeling/reaching, work pace, concentration, standing/sitting for long periods, and meeting work demands. Overall score ranges from 0 to 36 points and higher measures indicate greater limitation [21].

WPAI:RA contains six questions to measure disabilities in paid and unpaid work in the last seven days. Results include four scores that summarize the percentage of: work time missed due to health; impairment while working due to health; activity impairment due to health; and Overall work impairment score due to health problems. The scores ranges from 0 to 100 points and higher measures indicate greater limitation in each domain [22].

WLQ-25 is composed by 25 -items and focuses on presenteeism and the proportion of work-time with limitation as opposed to the degree of difficulty or severity of limitations. It assesses four dimensions of presenteeism while at work: physical demands, time management, mental-interpersonal demands and output demands. Questions regarding work productivity and performance over the past 2-4 weeks were answered using a 5-point Likert scale, ranging from 0 (none of the time) to 4 (all of the time). Each scale was scored separately and scores were converted from 0 to 100 , where higher scores represent increased limitations [23, 24].

\section{Health-related quality of life}

SF-36 is a composed by 36 questions grouped into 8 domains (physical functioning, role-physical, bodily pain, general health, vitality, social functioning, roleemotional, and mental-health). Two summary measures are also provided: Physical Component Summary (PCS) and Mental Component Summary (MCS). The raw score of each dimension was converted into a value from 0 (worst possible health state) to 100 (best possible health state). All scales were standardized to the 1998 general 
US population using the norm base scale algorithm. Scale score $<45$ can be interpreted as being below the average range for the general population [25].

EQ-5D-3 L assesses health status through 5 domains (mobility, self-care, usual activities, pain/discomfort and anxiety/depression) considering 3 levels: no problems, some problems, extreme problems. Additionally, a Visual Analogue Scale (EQ-VAS) records respondents' selfrated health from "Best imaginable health state" $=0$ to "Worst imaginable health state" $=100$. Utility score represents a scale between death $=0$ and perfect health $=1$ and is derived from the answers to each dimension, calculated using the United Kingdom algorithm [26, 27].

\section{Disease progression}

Multi-Dimensional Health Assessment Questionnaire (MDHAQ) was used in the first and last visits to evaluate disease activity, which is a 4-domains measure: physical function (FN), pain (PN), Rheumatoid Arthritis Disease Activity Index (RADAI) and patient global estimate (PTGL). Final disease activity measure was obtained using Rheumatology Assessment Patient Index Data 3 measures (RAPID3), calculated from the answers of three MDHAQ domains (FN, PN and PTGL). RAPID3 score ranges from 0 to 30 points and classify patients into four groups: remission ( $\leq 3$ points), low severity (3.1 to 6 points), moderate severity (6.1 to 12 points) and high severity ( $>12$ points) [28]. Disease progression was defined as disease activity modification during the study period, considering the interval between the first and last visits, classified in the following categories: Improvement or maintenance; and Worsen.

\section{Sample size calculation}

PROSE RA study was primarily designed to assess how RA impacts on work productivity and HRQoL at baseline and also to analyze association with exposure variables. Thus, sample size was calculated based on assumptions of potential differences between these groups from published data [20, 29-32]. Simulations for a descriptive approach were performed to assure an adequate precision of estimated parameter using two different margins of error: a score difference observed by each subgroup and a fixed value of $5.0 \%$ of the maximum in each scale. Considering $a=0.05$ and a power of 0.80 and adopting a conservative approach, the higher estimated sample size was select $(N=280)$ assuring that the study would have power to detect the smallest difference.

\section{Statistical analysis}

Descriptive analysis was performed through means and standard deviation to quantitative variables, and frequency to qualitative variables. Data were tested for normal distribution using the Shapiro-Wilk and Kolmogorov-Smirnov tests. To compare means, variables with normal distribution were analyzed by the Student's t-test and those with non-normal distribution by Mann-Whitney or Wilcoxon nonparametric tests. Linear regression was used to build a multivariate model to assess the association between outcomes and exposure variables, controlled for possible confounders and interactions. Due to the small sample size for each country, bivariate and multivariate analyses were performed considering the entire sample only. Analysis of the impact of disease progression (longitudinal) on work productivity and HRQoL was assessed through the difference on mean scores between study visits 1 and 5 . Thus, these differences are shown and tested among disease progression groups: "Improvement or maintenance" and "Worsening".

Only valid answers were used for all PROs. Guidelines $[21,23,25,26,28]$ from each standardized instruments report different strategies to deal with missing data as follows: MDHAQ (if at least one question left unanswered in any domain, patient excluded from this specific analysis); WALS (patient excluded from specific analysis, if more than two questions left unanswered; values estimated through the mean of answered data, if until two questions left unanswered or the answer of any question "refused"); WPAI:RA (questionnaires with missing answers did not have the corresponding score calculated); WLQ (patient excluded from specific analysis if $>2$ questions were left unanswered); SF-36 (missing values estimated through the mean of answered data in the same scale for patients with responses for at least half of the domain questions); and EQ-5D-3 L (patient excluded of specific analysis, if any question left unanswered).

Stata (version MP12) and R Project (version 3.2) were adopted to perform the analysis with a $95 \%$ confidence interval and $p$-value $\leq 0.05$.

\section{Ethical approval}

Research was reviewed and approved by Independent Ethics Committee according to study site and responsible committees are listed in Additional file 1: Table S1. All procedures were in accordance with the ethical standards from each country and with the Helsinki declaration and its later amendments or comparable ethical standards. Written informed consent and authorization to use and/or disclose his/her anonymised health data was obtained from all participants.

\section{Results}

\section{Sociodemographic and clinical characteristics}

The study enrolled 290 patients at baseline: 75 (25.9\%) from Argentina, 75 (25.9\%) from Mexico, 72 (24.8\%) 
from Colombia and 68 (23.4\%) from Brazil. Sociodemographic and clinical characteristics are shown in Tables 1 and 2.

NA $=$ Not applicable.

RA $=$ Rheumatoid Arthritis.

$S D=$ Standard Deviation .

DMARDs = Disease-Modifying Antirheumatic Drugs.

RA $=$ Rheumatoid Arthritis.

RAPID3 = Rheumatology Assessment Patient Index

Data 3 measures.

$S D=$ Standard Deviation .

\section{Work productivity at baseline}

Table 3 shows descriptive analysis of WALS, WPAI:RA and WLQ-25. Results stratified in accordance with exposure variables for total sample and final models for each questionnaires' measures are shown in Additional file 1: Tables $\mathrm{S} 2$ and $\mathrm{S} 3$, respectively.

$R A=$ Rheumatoid Arthritis.

$S D=$ Standard Deviation .

WALS $=$ Workplace Activity Limitation Scale.

WLQ-25 = 25-item Work Limitations Questionnaire.

WPAI:RA = Work Productivity and Activity Impairment Questionnaire - Rheumatoid Arthritis.

Overall mean WALS score in total sample was 9.0 $(\mathrm{SD}=6.1)$, ranging from $8.2(\mathrm{SD}=6.3)$ in Mexico to 10.6 $(\mathrm{SD}=6.8)$ in Brazil. At least $40.3 \%$ of RA patients reported some disability in each of the WALS questions. Main limitations informed in the workplace were difficulty to crouch, bend, kneel or work in awkward positions $(84.0 \%)$ and to lift, carry or move objects (80.1\%). A similar pattern was observed among participating countries. Multivariate analysis showed that higher work limitation according to WALS was observed when patients had medication coverage/insurance $(\beta=2.35$; $95 \% \mathrm{CI}=0.21$ to $4.50 ; p=0.031)$ and increased disease activity level $(\beta=3.67 ; 95 \% \mathrm{CI}=3.01$ to $4.34 ; p<0.001)$.

Employment was reported by $60.3 \%$ of the total respondents of WPAI:RA - 72.6\% in Argentina, $62.5 \%$ in Colombia, $57.3 \%$ in Mexico and $44.2 \%$ in Brazil (data not shown). Considering total sample, the ability to perform usual activities due to RA was the mostly affected category $(42.5 \% ; \mathrm{SD}=30.9)$, and presenteeism was the most impaired productivity dimension $(29.5 \% ; \mathrm{SD}=$ 28.8). All participating countries had a comparable pattern. In WPAI:RA final multivariate model, having previous orthopedic surgery $(\beta=-1.80 ; 95 \% \mathrm{CI}=-3.28$ to $0.31 ; p=0.020)$, medication coverage/insurance $(\beta=-$ $2.69 ; 95 \% \mathrm{CI}=-4.99$ to $-0.39 ; p=0.024)$ and consultations in the last 3 months $(\beta=-1.22 ; 95 \% \mathrm{CI}=-2.39$ to $0.05 ; p=0.042)$ decreased absenteeism; while reporting having performed ancillary tests increased $(\beta=1.27$; $95 \% \mathrm{CI}=0.19$ to $2.53 ; p=0.023)$. Each disease activity level significantly increased presenteeism $(\beta=15.91$;
$95 \% \mathrm{CI}=12.10$ to $19.72 ; p<0.001)$. The "absenteeism and presenteeism" category was decreased by: medication coverage/insurance $(\beta=-2.70 ; 95 \% \mathrm{CI}=-4.95$ to -0.45 ; $p=0.021)$ and consultations in the last 3 months $(\beta=-$ $1.26 ; 95 \% \mathrm{CI}=-2.40$ to $-0.11 ; p=0.033)$. Having performed ancillary tests in the last 3 months $(\beta=1.27$; $95 \% \mathrm{CI}=0.19$ to $2.53 ; \mathrm{p}=0.023)$ and previous orthopedic surgery $(\beta=1.80 ; 95 \% \mathrm{CI}=0.32$ to $3.22 ; p=0.019)$ increased "absenteeism and presenteeism". Impairment in regular daily activities was decreased by overweight/ obesity $(\beta=-7.14 ; 95 \% \mathrm{CI}=-14.03$ to $-0.25 ; p=0.042)$; and increased by disease activity $(\beta=19.47 ; 95 \% \mathrm{CI}=$ 16.67 to 22.28; $p<0.001)$ and female group $(\beta=12.14$; $95 \% \mathrm{CI}=1.08$ to $23.21 ; p=0.032$ ).

For the total sample, WLQ-25 physical demands scale (40.3\%) was the most affected due to RA, ranging from $44.0 \%$ in Mexico to $35.5 \%$ in Colombia. Productivity loss represented by WLQ-25 index was 7.0\% (SD = 5.1), ranging from 7.8\% $(\mathrm{SD}=5.6)$ in Colombia to $5.9 \%(\mathrm{SD}=$ 4.5) in Brazil. In multivariate final model, higher educational levels - technical or trade school to complete postgraduate education $-(\beta=-0.36 ; 95 \% \mathrm{CI}=-0.70$ to -0.02 ; $p=0.039)$ and having undergone a previous orthopedic surgery $(\beta=-0.50 ; 95 \% \mathrm{CI}=-1.00$ to $-0.01 ; p=0.045)$ decreased productivity losses.

\section{Health-related quality of life}

Table 4 shows descriptive analysis of HRQoL measures. These measures were stratified in accordance with exposure variables for total sample and final model for each of the questionnaires' measures are shown in Additional file 1: Tables S4 and S5.

EQ-5D-3 $L=$ EuroQol 5 Dimensions Questionnaire 3 level version.

MCS = Mental Component Score.

PCS=Physical Component Score.

RA $=$ Rheumatoid Arthritis.

$S D=$ Standard Deviation.

SF-36 = 36-Item Short Form Health Survey.

Considering data for general population, seven of eight scales from SF-36 questionnaire in total sample have shown scores slightly below the reference value (lower limit: 45). Value observed in the scale "Vitality" for total sample was the only within the range of 45 and 55. The same pattern was observed in each of the countries, with the exception of Mexico, that has shown scores within the range for the scales "Vitality" (49.8; $\mathrm{SD}=10.3$ ) and "Mental Health" (46.7; SD = 11.6). All PCS measures were below the reference value for total sample and also for each country. Mean estimated for MCS was above reference value for total sample, and also in Brazil and Mexico. In the multivariate analysis, patients who had performed ancillary tests in the last 3 months had a decrease in 
Table 1 Description of studied sociodemographic characteristics among RA patients at baseline

\begin{tabular}{|c|c|c|c|c|c|c|c|c|c|c|}
\hline \multirow[t]{3}{*}{ Characteristic } & \multirow{2}{*}{\multicolumn{2}{|c|}{$\frac{\text { Argentina }}{(\boldsymbol{N}=75)}$}} & \multirow{2}{*}{\multicolumn{2}{|c|}{$\frac{\text { Brazil }}{(\boldsymbol{N}=68)}$}} & \multirow{2}{*}{\multicolumn{2}{|c|}{$\frac{\text { Colombia }}{(\boldsymbol{N}=72)}$}} & \multirow{2}{*}{\multicolumn{2}{|c|}{$\frac{\text { Mexico }}{(\boldsymbol{N}=75)}$}} & \multirow{2}{*}{\multicolumn{2}{|c|}{$\frac{\text { Total }}{(\boldsymbol{N}=290)}$}} \\
\hline & & & & & & & & & & \\
\hline & $\mathrm{N}$ & $\%$ & $\mathrm{~N}$ & $\%$ & $\mathrm{~N}$ & $\%$ & $\mathrm{~N}$ & $\%$ & $\mathrm{~N}$ & $\%$ \\
\hline Age [Mean/SD] & 43.4 & 7.8 & 45.9 & 6.8 & 49.3 & 8.9 & 41.6 & 9.5 & 43.7 & 8.4 \\
\hline \multicolumn{11}{|l|}{ Gender } \\
\hline Female & 68 & 90.7 & 59 & 86.8 & 64 & 88.9 & 70 & 93.3 & 261 & 90.0 \\
\hline \multicolumn{11}{|l|}{ Race } \\
\hline Mestizo & NA & NA & 15 & 22.1 & 45 & 62.5 & 72 & 96 & 132 & 45.6 \\
\hline Caucasian/White & 37 & 49.3 & 36 & 52.9 & 3 & 4.2 & NA & NA & 76 & 26.2 \\
\hline Hispanic/Latin & 37 & 49.3 & NA & NA & 21 & 29.2 & NA & NA & 58 & 20.0 \\
\hline African American & NA & NA & 14 & 20.6 & 1 & 1.4 & - & - & 15 & 5.2 \\
\hline Brazilian Indian & NA & NA & 1 & 1.5 & NA & NA & NA & NA & 1 & 0.3 \\
\hline Native American & NA & NA & NA & NA & 1 & 1.4 & NA & NA & 1 & 0.3 \\
\hline Other & NA & NA & 2 & 2.9 & NA & NA & NA & NA & 2 & 0.7 \\
\hline \multicolumn{11}{|l|}{ Marital Status } \\
\hline Married & 41 & 54.7 & 35 & 51.5 & 30 & 41.7 & 41 & 54.7 & 147 & 50.7 \\
\hline Single/Not ever married & 20 & 26.7 & 19 & 27.9 & 24 & 33.3 & 18 & 24.0 & 81 & 27.9 \\
\hline Partner/Common law & 8 & 10.7 & 4 & 5.9 & 11 & 15.3 & 5 & 6.7 & 28 & 9.7 \\
\hline Divorced & 2 & 2.6 & 5 & 7.4 & 1 & 1.3 & 7 & 9.3 & 15 & 5.2 \\
\hline Separated & 4 & 5.3 & - & - & 3 & 4.2 & 1 & 1.3 & 8 & 2.8 \\
\hline Widowed & - & - & 3 & 4.3 & 3 & 4.2 & 2 & 2.7 & 8 & 2.7 \\
\hline \multicolumn{11}{|l|}{ Educational level } \\
\hline Incomplete High School & 18 & 24.0 & 32 & 47.1 & 15 & 20.8 & 6 & 8.0 & 71 & 24.5 \\
\hline Complete High School & 17 & 22.7 & 18 & 26.5 & 12 & 16.7 & 17 & 22.7 & 64 & 22.1 \\
\hline Technical or trade school & NA & NA & 5 & 7.4 & 16 & 22.2 & 20 & 26.7 & 41 & 14.1 \\
\hline Complete or incomplete graduate degree & 35 & 46.7 & 4 & 5.8 & 20 & 27.8 & 18 & 24.0 & 77 & 26.6 \\
\hline Complete postgraduate & 2 & 2.6 & 4 & 5.8 & 9 & 12.5 & 4 & 5.3 & 19 & 6.6 \\
\hline \multicolumn{11}{|l|}{ Primary occupation } \\
\hline Professional or technical & 16 & 21.3 & 4 & 5.9 & 18 & 25.0 & 13 & 17.3 & 51 & 17.6 \\
\hline Office worker & 13 & 17.3 & 3 & 4.4 & 13 & 18.1 & 4 & 5.3 & 33 & 11.4 \\
\hline Service worker & 9 & 12.0 & 10 & 14.7 & 11 & 15.3 & 7 & 9.3 & 37 & 12.8 \\
\hline Sales & 7 & 9.3 & 2 & 2.9 & 6 & 8.3 & 6 & 8.0 & 21 & 7.2 \\
\hline Manager, official or proprietor & 4 & 5.3 & 1 & 1.5 & 6 & 8.3 & 5 & 6.7 & 16 & 5.5 \\
\hline Craftsman or foreman & 2 & 2,7 & 2 & 2.9 & 2 & 2.8 & 1 & 1.3 & 7 & 2.4 \\
\hline Operative & 1 & 1.3 & 3 & 4.4 & 3 & 4.2 & 1 & 1.3 & 8 & 2.8 \\
\hline Other & 12 & 16.0 & 6 & 8.8 & 11 & 15.3 & 34 & 45.3 & 69 & 21.7 \\
\hline $\mathrm{Nl}$ & 11 & 14.7 & 37 & 54.4 & 2 & 2.8 & 4 & 5.3 & 54 & 18.6 \\
\hline \multicolumn{11}{|l|}{ Smoking habit } \\
\hline Nonsmokers & 40 & 53.3 & 39 & 57.4 & 47 & 65.3 & 51 & 68.0 & 177 & 61.0 \\
\hline Former smokers & 22 & 29.3 & 17 & 25.0 & 20 & 27.8 & 12 & 16.0 & 71 & 24.5 \\
\hline Current smokers & 13 & 17.4 & 12 & 17.6 & 5 & 6.9 & 11 & 14.7 & 41 & 14.2 \\
\hline
\end{tabular}

the PCS score $(\beta=-2.33 ; 95 \% \mathrm{CI}=-4.17$ to $-0.49 ; p=$ $0.013)$; and each category of disease activity, from remission to high severity, decreased the score of PCS, in at least 7.06 points $(\beta=-7.06 ; 95 \% \mathrm{CI}=-7.87$ to -
6.21; $p<0.001)$ and MCS, in at least 3.34 points $(\beta=$ $-3.34 ; 95 \% \mathrm{CI}=-4.72$ to $-1.96 ; p<0.001)$.

EQ-VAS mean score ranged from $64.4(\mathrm{SD}=21.5)$ in Brazil to 75.4 ( $\mathrm{SD}=21.6)$ in Mexico and for the whole 
Table 2 Description of studied clinical characteristics among RA patients at baseline

\begin{tabular}{|c|c|c|c|c|c|c|c|c|c|c|}
\hline \multirow[t]{3}{*}{ Characteristic } & \multirow{2}{*}{\multicolumn{2}{|c|}{$\frac{\text { Argentina }}{(\mathrm{N}=75)}$}} & \multirow{2}{*}{\multicolumn{2}{|c|}{$\frac{\text { Brazil }}{(N=68)}$}} & \multirow{2}{*}{\multicolumn{2}{|c|}{$\frac{\text { Colombia }}{(\mathrm{N}=72)}$}} & \multirow{2}{*}{\multicolumn{2}{|c|}{$\frac{\text { Mexico }}{(N=75)}$}} & \multirow{2}{*}{\multicolumn{2}{|c|}{$\frac{\text { Total }}{(N=290)}$}} \\
\hline & & & & & & & & & & \\
\hline & $\mathrm{N}$ & $\%$ & $\mathrm{~N}$ & $\%$ & $\mathrm{~N}$ & $\%$ & $\bar{N}$ & $\%$ & $\mathrm{~N}$ & $\%$ \\
\hline \multicolumn{11}{|l|}{ Clinical characteristics } \\
\hline Body Mass Index [Mean/SD] & 26.8 & 4.9 & 29.2 & 6.1 & 24.8 & 3.7 & 27.6 & 5.2 & 27.0 & 5.3 \\
\hline Comorbidities & 53 & 70.7 & 59 & 86.8 & 40 & 55.6 & 40 & 53.3 & 192 & 66.2 \\
\hline Patients who underwent at least one previous orthopedic surgery & 18 & 24.0 & 12 & 17.6 & 11 & 15.3 & 7 & 9.3 & 48 & 16.6 \\
\hline \multicolumn{11}{|l|}{ Disease characteristics } \\
\hline Disease duration (years) [Mean/SD] & 8.9 & 9.0 & 10.8 & 6.7 & 8.6 & 7.3 & 7.7 & 7.2 & 9.0 & 7.7 \\
\hline Time since symptoms onset (years) [Mean/SD] & 9.7 & 9.0 & 12 & 7.8 & 9.5 & 7.3 & 9.4 & 7.4 & 10.1 & 8.0 \\
\hline Patients with medication coverage/insurance & 68 & 90.7 & 47 & 69.1 & 69 & 95.8 & 55 & 73.3 & 239 & 82.4 \\
\hline Use of DMARDs & 66 & 88.0 & 60 & 88.2 & 62 & 86.1 & 69 & 92.0 & 260 & 89.7 \\
\hline \multicolumn{11}{|l|}{ Disease activity (RAPID3 score) } \\
\hline Remission & 9 & 12.0 & 3 & 4.4 & 6 & 8.3 & 15 & 20.0 & 33 & 11.4 \\
\hline Low severity & 17 & 22.7 & 1 & 1.5 & 9 & 12.5 & 11 & 14.7 & 38 & 13.1 \\
\hline Moderate severity & 14 & 18.7 & 23 & 33.8 & 21 & 29.2 & 21 & 28.0 & 79 & 27.2 \\
\hline High severity & 22 & 29.3 & 38 & 55.9 & 31 & 43.1 & 22 & 29.3 & 113 & 39.0 \\
\hline \multicolumn{11}{|l|}{ Direct medical resource utilization in the last three months } \\
\hline Patients with at least one outpatient visit & 58 & 77.3 & 52 & 76.5 & 58 & 80.5 & 56 & 74.7 & 224 & 77.2 \\
\hline Patients with at least one visit to perform tests & 47 & 62.7 & 48 & 70.6 & 45 & 62.5 & 49 & 65.3 & 196 & 67.9 \\
\hline Patients who underwent at least one surgery (any type) & 4 & 5.3 & 1 & 1.5 & 4 & 5.6 & 1 & 1.3 & 10 & 3.4 \\
\hline
\end{tabular}

sample was $69.8(\mathrm{SD}=20.4)$. Mean utility score was 0.67 $(\mathrm{SD}=0.23)$ for total sample and ranged from $0.62(\mathrm{SD}=$ $0.19)$ to $0.71(\mathrm{SD}=0.23)$ among countries. Final multivariate model for EQ-VAS has shown that patients with a longer disease duration ( $\geq 9$ years $)(\beta=-5.19 ; 95 \% \mathrm{CI}=$ -9.52 to $-0.85 ; p=0.019)$ and presenting worsening of disease activity level $(\beta=-10.74 ; 95 \% \mathrm{CI}=-12.81$ to 8.68; $\mathrm{p}<0.001$ ) have a decrease in the score. Beside this, use of DMARDs increased EQ-VAS score $(\beta=8.39$; $95 \% \mathrm{CI}=1.52$ to $15.25 ; p=0.020$ ).

Regarding utility scores from EQ-5D-3 L instrument, ancillary test multivariate analysis indicates that overweight/obese patients $(\beta=-0.06 ; 95 \% \mathrm{CI}=-0.11$ to $0.003 ; p=0.039)$ and those with a longer disease duration ( $\geq 9$ years) $(\beta=-0.05 ; 95 \% \mathrm{CI}=-0.10$ to -0.01 ; $p=0.012$ ) have a decrease in the utility score. Utility score is also reduced with the increase of the disease activity level $(\beta=-0.12 ; 95 \% \mathrm{CI}=-0.14$ to $-0.10 ; p<$ $0.001)$. On the other hand, mestizos patients showed an increasing in utility scores $(\beta=0.06 ; 95 \% \mathrm{CI}=0.01$ to $0.11 ; p=0.010)$.

\section{Disease progression and impact on work productivity and HRQoL}

It was observed a slightly higher mean of RAPID3 score in Visit $1(10.7 ; \mathrm{SD}=6.6)$ than in Visit 5 (9.7; $\mathrm{SD}=6.7)$, but no statistical significant difference was observed between these measures $(p=0.270)$. However, the majority of patients $(79.4 \%)$ has improved or maintained the disease activity level during the 1-year follow-up period.

Considering differences between the first and last study visits, worsening in the disease activity showed an association with an increase on impact on work productivity and HRQoL. Patients who had improvement/maintenance had also an improvement in the assessed measures and those who worsened also had a worsening in the scores, except for WLQ-25. However, a statistically significant difference was observed only for WALS $(p=0.001)$; WPAI:RA domains "presenteeism" ( $p=$ $0.020)$ and "impairment of regular daily activities" ( $p=$ $0.017)$; components of SF-36: physical $(p<0.001)$ and mental $(\mathrm{p}<0.001)$; and EQ-5D-3 L utility score $(p=$ $0.007)$ - Table 5.

EQ-5D-3 L =EuroQol 5 Dimensions Questionnaire 3 level version.

HRQoL = Health-Related Quality of Life.

WALS $=$ Workplace Activity Limitation Scale.

WLQ-25 = 25-item Work Limitations Questionnaire.

WPAI:RA = Work Productivity and Activity Impairment Questionnaire - Rheumatoid Arthritis.

$S D=$ Standard Deviation.

SF-36 = 36-Item Short Form Health Survey.

VAS=Visual Analogue Scale. 
Table 3 Work productivity assessed through WALS, WPAI:RA and WLQ-25 questionnaires among RA patients at baseline

\begin{tabular}{|c|c|c|c|c|c|c|c|c|c|c|}
\hline \multirow[t]{2}{*}{ Work Productivity } & \multicolumn{2}{|c|}{ Argentina } & \multicolumn{2}{|l|}{ Brazil } & \multicolumn{2}{|c|}{ Colombia } & \multicolumn{2}{|c|}{ Mexico } & \multicolumn{2}{|l|}{ Total } \\
\hline & Mean & SD & Mean & SD & Mean & SD & Mean & SD & Mean & SD \\
\hline WALS & \multicolumn{2}{|c|}{$N=52$} & \multicolumn{2}{|c|}{$N=22$} & \multicolumn{2}{|c|}{$N=64$} & \multicolumn{2}{|c|}{$\mathrm{N}=68$} & \multicolumn{2}{|c|}{$N=206$} \\
\hline 1.Get to and from work and maintain punctuality [N/\%] & 18 & 34.6 & 11 & 50.0 & 30 & 46.9 & 24 & 35.3 & 83 & 40.3 \\
\hline 2. Getting to the workplace [N/\%] & 26 & 50.0 & 11 & 50.0 & 43 & 67.2 & 36 & 52.9 & 116 & 56.3 \\
\hline 3. Sitting for long periods of time at your job [N/\%] & 17 & 32.7 & 10 & 45.5 & 38 & 59.4 & 34 & 50.0 & 99 & 48.1 \\
\hline 4. Standing for long periods of time at your job [N/\%] & 34 & 65.4 & 15 & 68.2 & 49 & 76.6 & 46 & 67.6 & 144 & 69.9 \\
\hline 5. Lift, carry or move objects [N/\%] & 39 & 75.0 & 18 & 81.8 & 52 & 81.3 & 56 & 82.4 & 165 & 80.1 \\
\hline 6. Working with your hands [N/\%] & 35 & 67.3 & 17 & 77.3 & 45 & 70.3 & 30 & 44.1 & 127 & 61.7 \\
\hline 7. Crouching, bend, kneel or work in awkward positions [N/\%] & 43 & 82.7 & 20 & 90.9 & 52 & 81.3 & 58 & 85.3 & 173 & 84.0 \\
\hline 8. Stretch out [N/\%] & 33 & 63.5 & 19 & 86.4 & 40 & 62.5 & 37 & 54.4 & 129 & 62.6 \\
\hline 9. With the schedule of hours of work that your job requires [N/\%] & 18 & 34.6 & 12 & 54.5 & 30 & 46.9 & 30 & 44.1 & 90 & 43.7 \\
\hline 10. With the pace of work that your job requires [N/\%] & 27 & 51.9 & 12 & 54.5 & 37 & 57.8 & 42 & 61.8 & 106 & 51.5 \\
\hline 11. Meet your current job demands [N/\%] & 25 & 48.1 & 14 & 63.6 & 36 & 56.3 & 37 & 54.4 & 110 & 53.4 \\
\hline 12. To concentrate and keep your mind on your work [N/\%] & 19 & 36.5 & 12 & 54.5 & 7 & 10.9 & 25 & 36.8 & 92 & 44.7 \\
\hline Overall score of WALS $(0-36)$ & 8.4 & 5.6 & 10.6 & 6.8 & 9.7 & 6.0 & 8.2 & 6.3 & 9.0 & 6.1 \\
\hline WPAI:RA & \multicolumn{2}{|c|}{$N=73$} & \multicolumn{2}{|c|}{$\mathrm{N}=52$} & \multicolumn{2}{|c|}{$N=72$} & \multicolumn{2}{|c|}{$\mathrm{N}=75$} & \multicolumn{2}{|c|}{$N=272$} \\
\hline \multicolumn{11}{|l|}{ Normal Daily Activities } \\
\hline \% Daily activity impairment due to RA & 34.0 & 28.2 & 56.1 & 27.4 & 46.7 & 29.0 & 36.5 & 33.8 & 42.5 & 30.9 \\
\hline \multicolumn{11}{|l|}{ Professional Activities } \\
\hline$\%$ Impairment while working due to RA (presenteeism)* & 23.9 & 23.9 & 32.6 & 26.8 & 40.5 & 32.2 & 23.1 & 28.5 & 29.5 & 28.8 \\
\hline$\%$ Work time missed due to RA (absenteeism)* & 12.0 & 27.5 & 5.8 & 23.5 & 7.5 & 21.6 & 8.4 & 18.8 & 9.0 & 23.2 \\
\hline$\%$ Overall work impairment due to RA (absenteeism and presenteeism)* & 10.3 & 25.0 & 5.9 & 23.9 & 7.6 & 21.9 & 8.9 & 20.3 & 8.6 & 22.6 \\
\hline$W L Q-25$ & \multicolumn{2}{|c|}{$N=59$} & \multicolumn{2}{|c|}{$N=36$} & \multicolumn{2}{|c|}{$N=43$} & \multicolumn{2}{|c|}{$N=53$} & \multicolumn{2}{|c|}{$N=191$} \\
\hline$\%$ work impairment due to physical demands & 41.1 & 24.7 & 37.7 & 24.1 & 35.5 & 24.0 & 44.0 & 28.7 & 40.3 & 21.4 \\
\hline$\%$ work impairment due to time demands & 33.5 & 24.7 & 29.3 & 30.6 & 32.4 & 26.8 & 27.9 & 29.0 & 30.9 & 28.0 \\
\hline$\%$ work impairment due to output demands & 27.6 & 24.4 & 18.1 & 19.3 & 29.9 & 25.8 & 22.7 & 23.3 & 24.9 & 23.8 \\
\hline$\%$ work impairment due to mental-interpersonal demands & 20.1 & 21.9 & 15.2 & 18.0 & 20.9 & 24.8 & 16.1 & 20.1 & 18.2 & 23.8 \\
\hline WLQ-25 index (\%) & 7.5 & 5.1 & 5.9 & 4.5 & 7.8 & 5.6 & 6.5 & 4.9 & 7.0 & 5.1 \\
\hline
\end{tabular}

\section{Discussion}

Our sample was comprised of patients from 4 Latin American countries, mostly middle-aged, female, from multiethnic origin, married with a technical or professional occupation. The educational level was welldistributed in the total sample, but Brazilian patients had a higher frequency of incomplete or complete high school only. This observation may be at least partially explained by the type of funding for study sites in the sample, once only Brazil had publicly-funded healthcare services enrolling patients and those facilities usually attend people with lower income and lower educational level in the country.

The burden of RA on Latin-American patients' work productivity and HRQoL was comprehensively assessed using standard PROs. Thus, it was possible to descriptively compare these data with findings from other contexts and countries. In summary, RA was related with presenteeism, indicating that patients are working with reduced performance and which seems to lead to unemployment [33-36]. For example, WPAI presenteeism measure (percentage of impairment while working due to RA) in our sample was $28.8 \%$, while healthy controls in a previous study in Sweden reported a mean impairment of 20.9\%. [37] Regarding HRQoL, physical aspect of the disease seems to be the major impairing condition [38-41]. Although these available data, there are several standard PROs that assess these outcomes from different perspectives, and this study analyzed a unique RA population using these different instruments.

Our results about burden of RA on work productivity assessed at baseline demonstrated an important impact of the disease on patients' life, related to several dimensions according to the instrument, and corroborate international data that patients are working with reduced performance. The overall work impairment due to RA at 
Table 4 Health-related quality of life assessed through SF-36 and EQ-5D-3 L questionnaires among RA patients at baseline

\begin{tabular}{|c|c|c|c|c|c|c|c|c|c|c|}
\hline \multirow[t]{2}{*}{ Health-related Quality of Life } & \multicolumn{2}{|c|}{ Argentina } & \multicolumn{2}{|l|}{ Brazil } & \multicolumn{2}{|c|}{ Colombia } & \multicolumn{2}{|c|}{ Mexico } & \multicolumn{2}{|l|}{ Total } \\
\hline & Mean & SD & Mean & SD & Mean & SD & Mean & SD & Mean & SD \\
\hline$S F-36$ & \multicolumn{2}{|c|}{$N=75$} & \multicolumn{2}{|c|}{$N=68$} & \multicolumn{2}{|c|}{$N=72$} & \multicolumn{2}{|c|}{$N=75$} & \multicolumn{2}{|c|}{$N=290$} \\
\hline Vitality & 46.9 & 10.9 & 47.0 & 9.5 & 47.9 & 10.2 & 49.8 & 10.3 & 47.9 & 10.3 \\
\hline Mental health & 42.5 & 11.4 & 44.3 & 12.3 & 43.7 & 10.4 & 46.7 & 11.6 & 44.3 & 11.5 \\
\hline Social functioning & 41.9 & 11.6 & 40.1 & 11.3 & 40.6 & 11.5 & 44.2 & 10.9 & 41.8 & 11.4 \\
\hline Bodily pain & 43.2 & 10.7 & 36.6 & 8.3 & 39.3 & 10.1 & 43.5 & 10.7 & 40.8 & 10.4 \\
\hline Role physical & 42.4 & 11.5 & 37.0 & 11.5 & 39.1 & 10.7 & 43.0 & 9.7 & 40.5 & 11.1 \\
\hline General health & 41.9 & 9.7 & 38.5 & 11.9 & 39.5 & 8.9 & 41.6 & 12.2 & 40.4 & 10.8 \\
\hline Role emotional & 39.9 & 13.9 & 41.2 & 13.5 & 37.5 & 11.6 & 42.1 & 11.3 & 40.2 & 12.7 \\
\hline Physical functioning & 38.5 & 11.0 & 32.0 & 8.6 & 37.6 & 10.6 & 40.2 & 12.2 & 37.2 & 11.1 \\
\hline Mental Component Score (MCS) & 43.4 & 11.9 & 47.3 & 11.9 & 43.9 & 9.9 & 47.2 & 11.3 & 45.4 & 11.3 \\
\hline Physical Component Score (PCS) & 41.8 & 9.8 & 33.6 & 9.6 & 38.7 & 9.1 & 41.5 & 10.7 & 39.1 & 10.3 \\
\hline$E Q-5 D-3 L$ & \multicolumn{2}{|c|}{$N=73$} & \multicolumn{2}{|c|}{$N=68$} & \multicolumn{2}{|c|}{$N=70$} & \multicolumn{2}{|c|}{$N=75$} & \multicolumn{2}{|c|}{$N=286$} \\
\hline Overall Value (0-100) & 71.5 & 16.6 & 64.4 & 21.5 & 67.4 & 20.2 & 75.4 & 21.6 & 69.8 & 20.4 \\
\hline Utility Score (0-1) & 0.67 & 0.25 & 0.62 & 0.19 & 0.66 & 0.25 & 0.71 & 0.23 & 0.67 & 0.23 \\
\hline
\end{tabular}

baseline in our sample was similar or lower than the observed in previous studies, depending on the characteristics of studied sample [33-35]. The work limitations related to presenteeism were also investigated using WALS measures and our patients are classified as having high severity of work place disability [36]. In the present study, all WLQ-25 subscales at baseline were higher than results observed in US populations of RA patients. A remarkable difference is noted in physical demands scale, indicating that Latin American patients are more limited in work environment mainly in this scale $[38,42]$.
When HRQoL was assessed at baseline, a major impact on physical aspects was observed, with lower physical SF-36 score (when compared with mental score), as described in the literature. EQ-VAS value estimated in our study was 69.8 ( $\mathrm{SD}=20.4)$, which is similar to those reported for Brazilian RA patients (mean score: 63 to 74) [43], and different from Mexican patients (mean score: 49.5) with osteoarthritis, RA or chronic low-back pain [44]. Utility measure calculated was 0.67 and no studies describing utility among Latin American RA patients were found to date. This measure is usually used to define public health policies, resource allocation and

Table 5 Comparison between differences in work productivity and HRQoL scores and disease progression from the first to the last study visit

\begin{tabular}{|c|c|c|c|c|c|c|}
\hline \multirow[t]{3}{*}{ Outcomes } & & \multicolumn{5}{|c|}{ Disease Progression } \\
\hline & & \multicolumn{2}{|c|}{ Improvement or maintenance } & \multicolumn{2}{|l|}{ Worsening } & \multirow[t]{2}{*}{ p-value } \\
\hline & & Mean Difference & SD & Mean Difference & SD & \\
\hline \multicolumn{7}{|c|}{ Work Productivity } \\
\hline WALS & & -0.9 & 4.1 & 1.9 & 4.2 & 0.001 \\
\hline \multirow[t]{4}{*}{ WPAI:RA } & Absenteeism & -0.7 & 25.3 & 5.0 & 14.7 & 0.118 \\
\hline & Presenteeism & -3.7 & 24.9 & 11.0 & 21.2 & $\underline{0.020}$ \\
\hline & Absenteeism and Presenteeism & -0.9 & 26.7 & 5.0 & 14.8 & 0.101 \\
\hline & Impairment of regular daily activities & -5.5 & 28.4 & 7.0 & 27.0 & $\underline{0.017}$ \\
\hline WLQ-25 & & 0.4 & 7.3 & -0.2 & 8.1 & 0.723 \\
\hline \multicolumn{7}{|l|}{ HRQoL } \\
\hline \multirow[t]{2}{*}{ SF-36 } & PCS & 2.9 & 7.1 & -1.7 & 7.1 & $\leq 0.001$ \\
\hline & MCS & 1.1 & 10.3 & -4.0 & 6.6 & $\leq 0.001$ \\
\hline \multirow[t]{2}{*}{ EQ-5D-3 L } & Overall VAS Value & 5.2 & 22.8 & -1.4 & 17.7 & 0.142 \\
\hline & Utility score & 0.03 & 0.25 & -0.06 & 0.18 & 0.007 \\
\hline
\end{tabular}


evaluation of services and programs, as it works as a proxy of how people value changes in health status [45], highlighting the need for these studies in Latin America.

It is known that multiple factors act to generate work impairment and poor HRQoL [46]. Obesity, living without partner, being mestizo, the presence of comorbidities, having medication insurance/coverage, longer disease duration, having performed ancillary test and consultations and a previous orthopedic surgery were associated with a worsening in work productivity and/or HRQoL. An improvement in the assessed PROs scores was associated with a higher educational level, having medication insurance/coverage, being mestizo, having recently performed ancillary test and consultations, a history of previous orthopedic surgery and use of DMARDs. Some variables behaved as protective or risk factors, depending on the instrument assessed, suggesting that these relationships still needs to be further addressed. Also, unexpectedly, obesity and overweight were associated with reduced impairment in regular daily activities in the WPAI analysis, as compared to underweight/normal BMI values. This finding seems in conflict with our observation that obese/overweight individuals have worse quality of life (EQ-5D-3 L utility score) and could not be explained by our data. A similar pattern was observed for the association between greater work limitations according to WALS and medication coverage/insurance. Potential confounders not collected in our study may play in this association.

With exception of WLQ-25, all PROs were associated with disease activity. The hypothesis that the disease activity may have a great impact in these aspects of patients' life arises from the presence of joint damage and loss of physical function in RA, which seems to be a prognostic factor in the ability to keep or get a new job $[14,47]$. This relationship was also observed in the longitudinal analysis, and confirms the finding from cross-sectional analysis showing that disease worsening is associated with an increase of the impact on work productivity and a decrease of HRQoL scores. Although no studies in the literature have assessed this relationship over time, this finding corroborates the main goals proposed by EULAR (The European League Against Rheumatism) and ACR (American College of Rheumatology) - o since the disease is not entirely curable, RA therapy must aim to reach disease remission, and if it is not possible, to achieve low disease activity reflecting on patients' professional and personal lives [10, 11]. About this aspect, it is important to notice that in the studied population, most patients had moderate or high disease activity at baseline and maintained it during the 1-year follow-up. Considering the recommendations for strategies of close monitoring and prompt therapy adjustments to achieve low disease activity or remission, this observation suggests that this is a particularly refractory population or that the management could be suboptimal. Further analyses of the data, including medication use, will be done to address this issue.

The aforementioned associations of HRQoL and work productivity among different stratum of study population were not yet well established and, thus, more studies are needed in order to infer a causal relationship [14, 40, 46, 48-53]. However, it is important that healthcare professionals stay alert to those characteristics during RA patients' management and also patients, families and the society, with the aim to minimize its effects on patients' professional and personal lives. It is worth mentioning that health systems should be investing in strategies and technologies targeting disease activity control among RA patients, once this seems to be a variable strongly related to higher burden not only to patients, but also the society. The data presented here will certainly be useful to better estimate the cost-effectiveness of these treatment strategies, invaluable information for optimizing the use limited health resources in relatively low-income countries, particularly nowadays with the growing number of costly anti-rheumatic drugs available.

This was the first study conducted in countries from Latin America with the aim to assess RA patients work productivity and HRQoL. This study adds knowledge in an area scarcely studied and improves global disease comprehension about burden of RA in Latin America.

\section{Conclusion}

This study highlights the importance of regular and timely disease management for RA patients, specially focusing on the need to decrease disease activity to promote better results in PROs. An increase in disease activity was responsible for a significant decrease in HRQoL, and a significant increase in workplace disabilities, leading to a more difficult time in maintaining or seeking job opportunities. Also, multiple factors were identified that seem to be associated with work impairment and HRQoL, but as for the protective factors, further research is still needed. This study's results highlight the need for a more comprehensive and holistic approach to RA management and that all relevant stakeholders (from families to HR managers) should be aware of RA's burden in patients' everyday life. Also, it sheds some light in a subject that is often overlooked, adding to the evidence that the burden of RA in QoL is significant. Finally, the knowledge of the burden of disease in Latin America is often limited, and this study contributes to the ever-increasing need to raise awareness so that resource allocation is focused on tackling this issue. 


\section{Supplementary information}

Supplementary information accompanies this paper at https://doi.org/10. 1186/s42358-019-0090-8

Additional file 1: Table S1. Independent Ethics Committee/Institutional Review Board approvals. Table S2. Work productivity assessed through WALS, WPAl:RA and WLQ-25 questionnaires among several exposure groups of RA patients at baseline. Table S3. Final model for the association between work productivity (WALS, WPAI:RA and WLQ-25 scores) and exposure groups at baseline. Table S4. Health-related quality of life assessed through SF-36 and EQ-5D-3L questionnaires among several exposure groups of RA patients at baseline. Table S5. Final model for the association between health-related quality of life (SF-36 and EQ-5D-3L scores) and exposure groups at baseline.

\section{Abbreviations}

ACR: American College of Rheumatology; DMARDs: Disease-Modifying Antirheumatic Drugs; EQ-5D-3 L: EuroQol 5 Dimensions Questionnaire 3 level version; EQ-VAS: EQ Visual Analogue Scale; FN: Physical function; HRQoL: Health related quality of life; MCS: Mental Component Summary; MDHAQ: Multi-Dimensional Health Assessment Questionnaire; PCS: Physical Component Summary; PN: Pain; PROs: Patient-reported outcomes; PROSE RA study: Patient Reported Outcomes Survey of Employment among patients with RA; PTGL: Patient's global assessment; RA : Rheumatoid Arthritis; RADAI: Rheumatoid Arthritis Disease Activity Index; RAPID3: Rheumatology Assessment Patient Index Data 3 measures; SD: Standard Deviation; SF36: 36-Item Short Form Health Survey; WALS: Workplace Activity Limitation Scale; WLQ-25: 25-Item Work Limitations Questionnaire; WPAI:RA: Work Productivity and Activity Impairment Questionnaire - Rheumatoid Arthritis

\section{Acknowledgments}

ANOVA Health Consulting Group provided assistance on study development and manuscript preparation, funded by AbbVie. Maíra Takemoto and Ana Carolina Padula Ribeiro Pereira from ANOVA provided medical writing assistance and editorial support with this manuscript. Diogo Morais from Eurotrials - Scientific Consultants Ltda. provided medical writing assistance and editorial support with this manuscript, funded by AbbVie. AbbVie participated in the study design and conduct, interpretation of data, review and approval of the content. All the authors had access to all relevant data and participated in writing, review, and approval of this manuscript.

\section{Data availability}

The datasets generated during and/or analysed during the current study are available from the corresponding author on reasonable request.

\section{Authors' contributions}

All authors meet the ICMJE authorship criteria, giving substantial contribution to the conception or design of the work, data acquisition and analysis, drafting or reviewing the work for intellectual content and giving final approval of the version to be published. The authors agree to be accountable for all aspects of the work in ensuring that questions related to the accuracy or integrity of any part of the work are appropriately investigated and resolved.

All authors have approved the manuscript for submission.

\section{Funding}

PROSE study was funded by AbbVie.

\section{Ethics approval and consent to participate}

Research was reviewed and approved by Independent Ethics Committee according to study site and responsible committees are listed in Additional file 1: Table S1. All procedures were in accordance with the ethical standards from each country and with the Helsinki declaration and its later amendments or comparable ethical standards. Written informed consent and authorization to use and/or disclose his/her anonymised health data was obtained from all participants.

\section{Consent for publication}

All authors consent to publish the manuscript in Advances in Rheumatology.

\section{Competing interests}

The authors declare that they have no competing interests.

\section{Author details}

${ }^{1}$ Universidade Federal do Rio Grande do Sul, Hospital de Clínicas de Porto Alegre, Porto Alegre, Brazil. ${ }^{2}$ Centro Paulista de Investigações Clínicas (CEPIC), São Paulo, Brazil. ${ }^{3}$ Universidade Federal de São Paulo, São Paulo, Brazil. ${ }^{4}$ Morales Vargas Centro de Investigación, Guanajuato, Mexico. ${ }^{5}$ Fundación Instituto de Reumatología Fernando Chalem, Bogotá, Colombia. ${ }^{6}$ Centro Integral de Reumatología - Reumalab, Medellín, Colombia. ${ }^{7}$ Centro de Investigaciones en Enfermedades Reumáticas (CIER), Buenos Aires, Argentina. ${ }^{8}$ Desarrollos Biomédicos y Biotecnológicos, Monterrey, Mexico. ${ }^{9}$ Circaribe, Barranquilla, Colombia. ${ }^{10} \mathrm{CEIM}$ Investigaciones Medicas, Buenos Aires, Argentina. ${ }^{11}$ Instituto Médico Especializado (IME), Buenos Aires, Argentina. ${ }^{12}$ AbbVie Farmacêutica Ltda, São Paulo, Brazil. ${ }^{13}$ Unidad de Investigación en Enf. Crónico-Degenerativas, Guadalajara, Mexico.

Received: 1 November 2018 Accepted: 21 October 2019

Published online: 09 November 2019

\section{References}

1. Smolen JS, Steiner G. Therapeutic strategies for rheumatoid arthritis. Nat Rev Drug Discov. 2003;2:473-88.

2. Choy EH, Panayi GS. Cytokine pathways and joint inflammation in rheumatoid arthritis. N Engl J Med. 2001;344:907-16.

3. Drosos AA. Newer immunosuppressive drugs: their potential role in rheumatoid arthritis therapy. Drugs. 2002;62:891-907.

4. Goldring SR. Pathogenesis of bone and cartilage destruction in rheumatoid arthritis. Rheumatology (Oxford) 2003;42 Suppl 2:ii11-6.

5. Lee SJ-A, Kavanaugh A. Pharmacological treatment of established rheumatoid arthritis. Best Pract Res Clin Rheumatol. 2003;17:811-29.

6. Lindqvist E. Course of radiographic damage over 10 years in a cohort with early rheumatoid arthritis. Ann Rheum Dis. 2003;62:611-6.

7. Burgos-Vargas R, Catoggio LJJ, Galarza-Maldonado C, Ostojich K, Cardiel $\mathrm{MHH}$. Current therapies in rheumatoid arthritis: a Latin American perspective. Reumatol Clin. 2013;9:106-12.

8. Alarcón GS. Epidemiology of rheumatoid arthritis. Rheum Dis Clin N Am. 1995;21:589-604.

9. Firestein GS. Etiology and pathogenesis of rheumatoid arthritis. In: Kelley's Textbook of Rheumatology. Philadelphia; 1999. p. 851-97.

10. Smolen JS, Landewé R, Breedveld FC, Buch M, Burmester G, Dougados M, et al. EULAR recommendations for the management of rheumatoid arthritis with synthetic and biological disease-modifying antirheumatic drugs: 2013 update. Ann Rheum Dis 2013;0:1-18.

11. Singh JA, Saag KG, Bridges SL, Akl EA, Bannuru RR, Sullivan MC, et al. 2015 American College of Rheumatology Guideline for the treatment of rheumatoid arthritis. Arthritis Rheumatol. 2016;68:1-26.

12. Krishnan E, Fries JF. Reduction in long-term functional disability in rheumatoid arthritis from 1977 to 1998:a longitudinal study of 3035 patients. Am J Med. 2003;115:371-6.

13. Puolakka K, Kautiainen $H$, Möttönen $T$, Hannonen $P$, Korpela M, Julkunen $H$, et al. Impact of initial aggressive drug treatment with a combination of disease-modifying antirheumatic drugs on the development of work disability in early rheumatoid arthritis: a five-year randomized followup trial. Arthritis Rheum. 2004;50:55-62.

14. Eberhardt K, Larsson B-M, Nived K, Lindqvist E. Work disability in rheumatoid arthritis--development over 15 years and evaluation of predictive factors over time. J Rheumatol. 2007;34:481-7.

15. Arnett FC, Edworthy SM, Bloch DA, McShane DJ, Fries JF, Cooper NS, et al. The American rheumatism association 1987 revised criteria for the classification of rheumatoid arthritis. Arthritis Rheum. 1988;31:315-24.

16. Reilly Associates. WPAI - translations. 2011. Available at: http://www. reillyassociates.net/WPAI_Translations.html.

17. Mapi Trust. Catalogue of questionnaires - HAQ-DI. 2011. Available at: http:// www.mapi-trust.org/services/questionnairelicensing/ cataloguequestionnaires/54-haq.

18. EuroQol Group. Available EQ-5D versions - EQ-5D. 2019. Available at: https://euroqol.org/eq-5d-instruments/available-eq-5d-versions/.

19. Qualimetrics. SF-36 and SF-36v2 Health Survey. Available at: https://www. optum.com/solutions/life-sciences/answer-research/patient-insights/sfhealth-surveys/sf-36v2-health-survey.html. Accessed May 7, 2019. 
20. Campolina AG, Bortoluzzo AB, Ferraz MB, Ciconelli RM. Mensuração de preferências em saúde: uma comparação do SF-6D Brasil com derivações do SF-36 em pacientes com artrite reumatóide. Acta Reum Port. 2010;35:200-6.

21. Tang K, Beaton DE, Boonen A, Gignac MAM, Bombardier C. Measures of work disability and productivity. Arthritis Care Res (Hoboken). 2011;63:S337-49.

22. Beck A, Crain AL, Solberg LI, Unutzer J, Glasgow RE, Maciosek MV, et al. Severity of depression and magnitude of productivity loss. Ann Fam Med. 2011:9:305-11.

23. Lerner D, Amick BC, Rogers WH, Malspeis S, Bungay K, Cynn D. The work limitations questionnaire. Med Care. 2001;39:72-85.

24. Lerner DJ, Amick BC, Malspeis S, Rogers WH. A national survey of healthrelated work limitations among employed persons in the United States. Disabil Rehabil. 2000;22:225-32.

25. Ware JE, Kosinsk M, Turner-Boweker, D.M. Gandek B. User's Manual for the SF-12v2 ${ }^{\circledR}$ Health Survey With a Supplement Documenting SF-12 ${ }^{\circledast}$ Health Survey):; 2002

26. The EuroQol Group. EQ-D User Guide; 2015.

27. Dolan P. Modeling valuations for EuroQol health states valuations modeling Med Care. 1997:35:1095-108

28. Pincus T. Scoring Instructions for R808 Multi-Dimensional Health Assessment Questionnaire (MDHAQ) and Rheumatology Assessment Patient Index Data (RAPID3). 2009;40:2009-2010.

29. Beaton DE, Tang K, Gignac M a M, Lacaille D, Badley EM, Anis AH, et al. Reliability, validity, and responsiveness of five at-work productivity measures in patients with rheumatoid arthritis or osteoarthritis. Arthritis Care Res (Hoboken). 2010;62:28-37.

30. Zhang W, Gignac MAM, Beaton D, Tang K, Anis AH. Productivity loss due to presenteeism among patients with arthritis: estimates from 4 instruments. J Rheumatol. 2010:37:1805-14.

31. Kievit W, Fransen J, Adang EMM, den Broeder AA, Bernelot Moens HJ, Visser $\mathrm{H}$, et al. Long-term effectiveness and safety of TNF-blocking agents in daily clinical practice: results from the Dutch rheumatoid arthritis monitoring register. Rheumatology. 2011;50:196-203.

32. Zhang W, Bansback N, Boonen A, Young A, Singh A, Anis AH. Validity of the work productivity and activity impairment questionnaire--general health version in patients with rheumatoid arthritis. Arthritis Res Ther. 2010;12:R177.

33. Chaparro Del Moral R, Rillo OL, Casalla L, Morón CB, Citera G. Cocco J a M, et al. Work productivity in rheumatoid arthritis: relationship with clinical and radiological features Arthritis. 2012;2012:137635.

34. Radner H, Smolen JS, Aletaha D. Remission in rheumatoid arthritis: benefit over low disease activity in patient-reported outcomes and costs. Arthritis Res Ther. 2014;16:R56.

35. Hone D, Cheng A, Watson C, Huang B, Bitman B, Huang X-Y, et al. Impact of etanercept on work and activity impairment in employed moderate to severe rheumatoid arthritis patients in the United States. Arthritis Care Res (Hoboken). 2013;65:1564-72.

36. Gignac M a M, Cao X, Tang K, Beaton DE. Examination of arthritis-related work place activity limitations and intermittent disability over four-and-ahalf years and its relationship to job modifications and outcomes. Arthritis Care Res (Hoboken) 2011;63:953-962.

37. Hasselrot $\mathrm{K}$, Lindeberg $\mathrm{M}$, Konings $\mathrm{P}$, Kopp $\mathrm{KH}$. Investigating the loss of work productivity due to symptomatic leiomyoma. PLoS One. 2018;13: e0197958.

38. Walker N, Michaud K, Wolfe F. Work limitations among working persons with rheumatoid arthritis: results, reliability, and validity of the work limitations questionnaire in 836 patients. J Rheumatol. 2005:32:1006-12.

39. Wolfe F, Michaud K, Choi HK, Williams R. Household income and earnings losses among 6,396 persons with rheumatoid arthritis. J Rheumatol. 2005;32: 1875-83.

40. Peláez-Ballestas I, Boonen A, Vázquez-Mellado J, Reyes-Lagunes I, Hernández-Garduño A, Goycochea MV, et al. Coping strategies for health and daily-life stressors in patients with rheumatoid arthritis, Ankylosing spondylitis, and gout: STROBE-compliant article. Medicine (Baltimore). 2015; 94:e600.

41. Contreras-Yáñez I, Cabiedes J, Villa AR, Rull-Gabayet M, Pascual-Ramos V. Persistence on therapy is a major determinant of patient-, physician- and laboratory- reported outcomes in recent-onset rheumatoid arthritis patients. Clin Exp Rheumatol. 2010;28:748-51.

42. Allaire S, Wolfe F, Niu J, Lavalley M, Michaud K. Work disability and its economic effect on 55-64-year-old adults with rheumatoid arthritis. Arthritis Rheum. 2005;53:603-8.
43. Pinheiro G da RC, Khandker RK, Sato R, Rose A, Piercy J. Impact of rheumatoid arthritis on quality of life, work productivity and resource utilisation: an observational, cross-sectional study in Brazil. Clin Exp Rheumatol 2013:31:334-340.

44. Ramos-Remus CR, Hunsche E, Mavros P, Querol J, Suarez R, ProExp Study Group. Evaluation of quality of life following treatment with etoricoxib in patients with arthritis or low-back pain: an open label, uncontrolled pilot study in Mexico. Curr Med Res Opin. 2004;20:691-8.

45. Campolina AG, Ciconelli RM. Qualidade de vida e medidas de utilidade parâmetros clínicos para as tomadas de decisão em saúde. Rev Panam Salud Pública. 2006;19:128-36.

46. Backman CL. Employment and work disability in rheumatoid arthritis. Curr Opin Rheumatol. 2004;16:148-52.

47. Vollenhoven RF. van, Cifaldi, M.A.; Ray S., Chen N., Weisman MH. Effect of inhibiting joint damage on work performance in patients with early rheumatoid arthritis: results from a companion study to premier. Ann Rheum Dis 2008:67:580.

48. Sokka T, Kautiainen H, Pincus T, Verstappen SMM, Aggarwal A, Alten R, et al. Work disability remains a major problem in rheumatoid arthritis in the 2000s: data from 32 countries in the QUEST-RA study. Arthritis Res Ther. 2010;12:R42.

49. Sokka T. Work disability in early rheumatoid arthritis. Clin Exp Rheumatol. 2003;21:571-4.

50. Jakobsson U, Hallberg IR. Pain and quality of life among older people with rheumatoid arthritis and/or osteoarthritis: a literature review. J Clin Nurs. 2002;11:430-43.

51. Sherman BW, Lynch WD. The relationship between smoking and health care, workers' compensation, and productivity costs for a large employer. J Occup Environ Med. 2013;55:879-84.

52. Chiu Y-M, Lai M-S, Lin H-Y, Lang H-C, Lee LJ-H, Wang J-D. Disease activity affects all domains of quality of life in patients with rheumatoid arthritis and is modified by disease duration. Clin Exp Rheumatol. 2014;32:898-903.

53. Gerhold K, Richter A, Schneider M, Bergerhausen HJ, Demary W, Liebhaber A, et al. Health-related quality of life in patients with long-standing rheumatoid arthritis in the era of biologics: Data from the German biologics register RABBIT. Rheumatol (United Kingdom) 2015;54:1858-1866.

\section{Publisher's Note}

Springer Nature remains neutral with regard to jurisdictional claims in published maps and institutional affiliations.
Ready to submit your research? Choose BMC and benefit from:

- fast, convenient online submission

- thorough peer review by experienced researchers in your field

- rapid publication on acceptance

- support for research data, including large and complex data types

- gold Open Access which fosters wider collaboration and increased citations

- maximum visibility for your research: over $100 \mathrm{M}$ website views per year

At $\mathrm{BMC}$, research is always in progress.

Learn more biomedcentral.com/submissions 